\title{
Purification and Molecular Cloning of Carp Ovarian Cystatin
}

\author{
Yuan-Jang Tsai, ${ }^{*}$ Geen-Dong Chang, $\dagger$ \\ Chang-Jen Huang, $\ddagger$ Yea-Sha Chang $\ddagger$ and Fore-Lien Huang* $\ddagger$ \\ - Department of Zoology and †Graduate Institute of Biochemical Sciences, National Taiwan University, \\ and łInstitute of Biological Chemistry, Academia Sinica, P.O. Box 23-106, Taipei, Taiwan
}

\begin{abstract}
The ovarian fluid of carp consists of many components. Using the antiserum against carp serum, Western blot analysis of ovarian fluid was done in order to distinguish substances synthesized by the ovary from those derived from the serum. Several ovary-specific substances were detected including a protein of $12 \mathrm{kDa}$ (p12), which was purified to homogeneity. Purified p12 displays a single band in SDS-PAGE under nonreducing condition and it can inhibit the enzymatic activity of papain with an apparent inhibition constant of 0.01 $\mathrm{nM}$. The primary structure of p12 was partially determined by Edman degradation and fully elucidated by molecular cloning. A cDNA of 531 bp encoding p12 was obtained. The precursor of p12 has 129 residues, including a signal peptide of 18 residues and a mature protein of 111 residues. The $\mathrm{N}$ - and $\mathrm{C}$-terminus of p12 are threonine and methionine, respectively. The p12 shares many common features of the family 2 cystatins of other species, including the similarity of the protein size (in the range of 110 to 120 residues), the presence of 4 cysteine residues and the occurrence of invariant residues throughout the molecule. COMP BIOCHEM PHYSIOL 113B, 573-580, 1996.
\end{abstract}

KEY WORDS. Teleost, carp, cystatin, protease inhibitor, ovary, ovarian fluid, molecular cloning, expression

\section{INTRODUCTION}

During ovulation in mammals, the extracellular matrix of the follicular wall is degraded by hydrolases $(11,28)$. The ovulated egg is freed from the follicular wall but is still surrounded by cumulus cells. In contrast, in fish, the oocyte is not enclosed by a prominent follicular wall, but each fish oocyte is surrounded by a layer of follicle cells, which attach firmly to oocyte. Ovulated eggs of fish are completely denuded, that is, free from follicle cells (42). Apparently, the extracellular matrix between the oocyte and surrounding follicle cells is degraded, presumably by hydrolases, during fish ovulation. Comparatively few studies have been undertaken to investigate the hydrolase involved in fish ovulation and no data are available at the present time.

It has been demonstrated that a cascade of hydrolases are synthesized or activated during ovulation in mammals by which the complicated extracellular matrix of the follicular wall is degraded $(11,28)$. Gonadotropins are the primary trigger activating the cascade (11). The synthesis or activation of hydrolases is under strict temporal and spatial control, occurring only during a certain period of ovulation and confined to the ovulatory follicle but not nonovulatory follicles (35). As a result, the extracellular matrix of ovulatory follicles is

Correspondence to: Fore-Lien Huang, Institute of Biological Chemistry, Academia Sinica, P.O. Box 23-106, Fax: 886-2-363-5038

Received 9 February 1995; revised 22 August 1995; accepted 31 August 1995. degraded whereas that of nonovulatory follicles remains intact. Furthermore, ovulatory follicles also synthesize a corresponding inhibitor for each hydrolase to prevent unwanted damage to other ovarian tissues (11). As a consequence, both hydrolases and their inhibitors can be detected simultaneously in a same ovulatory follicle. Mammalian follicular fluid is rich in hydrolases and their inhibitors, and is frequently used as source material to study the substances involved in ovulation $(12,18)$.

Under the action of gonadotropin, the permeability of blood vessels in the ovary increases, which causes imbibition in mammalian ovary (38). A similar phenomenon may also occur in fish since the water content of fish ovaries is greatly increased during ovulation induced by gonadotropin $(8,40)$. The fluid accompanying ovulated fish eggs (designated as ovarian fluid) may be equivalent to mammalian follicular fluid and thus also may contain hydrolases as well as corresponding inhibitors. We are interested in substances involved in fish ovulation, and have used fish ovarian fluid as the starting material for our studies. We now report the purification and characterization of a family 2 cystatin, an inhibitor of cysteine protease, present in the ovarian fluid of common carp.

\section{MATERIALS AND METHODS Materials}

Carp (Cyprinus carpio) were purchased from a local market. DEAE-TSK and CM-TSK gel were obtained from E. Merck 
(Darmstadt, Germany). The superdex $75 \mathrm{HR}$ column was purchased from Pharmacia LKB Biotechnology AB (Uppsala, Sweden). Guinea pig and rabbit were procured from The Animal Center of National Taiwan University (Taipei, Taiwan). Papain, diaminobenzidine, peroxidase-conjugated immunoglobulin $G(\operatorname{lgG})$ against $\operatorname{IgG}$ of guinea pig and rabbit, respectively, were obtained from Sigma Chemical Company ( $\mathrm{St}$ Louis, MO, U.S.A.). [L-3-trans-carboxyoxirane-2-carbonyl]L-leu-agmatine and carbobenzoxy-L-phenylalanyl-l-arginine 4 methyl-coumaryl-7-amide were obtained from Peptide Institute Inc. (Osaka, Japan). Trypsin of sequencing grade and $\mathrm{T}_{\mathrm{aq}}$ DNA polymerase were purchased from Promega Corporation (Madison, WI, U.S.A.). All other chemicals used were reagent grade.

\section{Preparation of Ovarian Fluid}

Carp were induced to ovulate by injection with the homogenate of carp pituitary gland. Carp pituitary glands were homogenized in $0.6 \% \mathrm{NaCl}-50 \mathrm{mM}$ sodium phosphate buffer, $\mathrm{pH} 7.0$ (PBS). The total body weight of pituitary gland donors was twice that of spawners. Pituitary gland homogenate was divided into two equal halves and each half was injected at a 6-hour interval into the spawner at the base of pectoral fin. Ovulation usually occurred 12 hours after the first injection. Ovulated eggs were collected and centrifuged $(500 \times \mathrm{g})$ at $4^{\circ} \mathrm{C}$ for 15 minutes. The supernatant was collected and stored at $-70^{\circ} \mathrm{C}$ until use.

\section{Induction of Antiserum}

The antiserum against carp serum was produced in a rabbit by subcutaneous injection as described by Harlow and Lane (19).

The antiserum against p12 was induced in guinea pig as described by Ichimura et al. (22).

\section{SDS-PAGE and Western Blot}

SDS-PAGE was prepared and performed as described by Schägger et al. (36). Gels were stained by Coomassie Blue. For Western blots, gels were transferred to a nitrocellulose filter. Following transfer, the nitrocellulose filter was blocked in 3\% skim milk in PBS for 30 minutes, followed by washing with PBS for 10 minutes three times and then incubated with antiserum (500-fold dilution in PBS) with $0.3 \% \mathrm{BSA}$ at $4^{\circ} \mathrm{C}$ overnight. After incubation, the filter was washed with PBS for 10 minutes three times, then incubated with peroxidaseconjugated secondary antibody (1000-fold dilution in PBS) with $0.3 \%$ BSA for 2 hours. The filter was again washed with PBS for 10 minutes three times. After washing the filter was incubated with the chromogenic substrate, diaminobenzidine, $(0.6 \mathrm{mg} / \mathrm{ml})$ and $0.3 \% \mathrm{H}_{2} \mathrm{O}_{2}$ in PBS for 5 minutes. The reaction was stopped by replacement with water.

\section{Purification of $p 12$}

Unless otherwise specified, all purification procedures were carried out at $4^{\circ} \mathrm{C}$. Ovarian fluid was acidified to $\mathrm{pH} 3.0$ with $1 \mathrm{~N} \mathrm{HCl}$, then centrifuged at $15,000 \times \mathrm{g}$ for $15 \mathrm{~min}$. The supernatant was dialyzed against $20 \mathrm{mM}$ Tris- $\mathrm{HCl}, \mathrm{pH} 8.0$ and then applied to a DEAE-TSK column $(25 \times 50 \mathrm{~mm})$ equilibrated with Tris- $\mathrm{HCl}$ buffer (above) at a flow rate of 1 $\mathrm{ml} / \mathrm{min}$. The flow-through fraction was collected and dialyzed against $40 \mathrm{mM}$ citrate buffer, $\mathrm{pH} 5.0$, then applied to a CM. TSK column $(25 \times 50 \mathrm{~mm})$ equilibrated with citrate buffer (above). After washing with equilibrating buffer, retained protein was eluted using a linear gradient of $\mathrm{NaCl}$ from 0 to 0.8 $\mathrm{M}$ in $40 \mathrm{mM}$ citrate buffer, $\mathrm{pH}$ 5.0. The first peak that contained p12 was pooled and dialyzed against $50 \mathrm{mM} \mathrm{NH}_{4} \mathrm{HCO}_{3}$ and concentrated by lyophilization. The lyophilized powder was dissolved in $50 \mathrm{mM} \mathrm{NH}_{4} \mathrm{HCO}_{3}$ to a concentration of 1 $\mathrm{mg} / \mathrm{ml}$ and applied to a superdex $75 \mathrm{HR}$ column $(10 \times 300$ $\mathrm{mm}$ ) on-line with a FPLC system of Pharmacia LKB Biotechnology at a flow rate of $0.5 \mathrm{ml} / \mathrm{min}$ at room temperature.

\section{Separation of Trypsin Digest of $p 12$ and Peptide Sequencing}

One hundred $\mu \mathrm{g}$ p12 from superdex $75 \mathrm{HR}$ column was dissolved in $100 \mu \mathrm{l}$ of $50 \mathrm{mM} \mathrm{NH} \mathrm{HCO}_{3}$ and digested with 2 $\mu \mathrm{g}$ trypsin at $37^{\circ} \mathrm{C}$ overnight. The digest was evaporated to dryness by speed vacuum.

The trypsin digest was dissolved in buffer $\mathrm{A}(0.07 \%$ trifluoroacetic acid, TFA in $5 \%$ acetonitrile) and subjected to a reverse phase HPLC column of ODS-3 $(4.6 \times 250 \mathrm{~mm}$, Whatman Inc., Clifton, NJ, U.S.A.) equilibrated with buffer A. The column was eluted with buffer $A$ for 10 minutes followed by a linear gradient of buffer B $(0.07 \%$ TFA in $80 \%$ acetonitrile) from $0 \%$ to $100 \%$ within 70 minutes and finally by buffer $B$ for another 10 minutes. The flow rate was $0.5 \mathrm{ml} /$ min.

Protein was electroblotted from a 10\% SDS-PAGE gel under reducing condition to a ProBlott membrane of Applied Biosystems (Foster City, CA, U.S.A.) (31). Protein bands were cut for sequencing. Amino-acid sequences were determined using a $477 \mathrm{~A}$ protein sequencer with an on-line $120 \mathrm{~A}$ phenylthiohydantoin analyzer of Applied Biosystems (20).

\section{Construction of Carp Ovarian cDNA Library and Screening of cDNA Encoding p12}

Total RNA was isolated from carp ovary containing fully grown oocytes obtained during breeding season as described by Chomczyski and Sacchi (9). Polyadenylated RNA was prepared by oligo-dT cellulose column chromatography and double-stranded cDNA was synthesized using oligo-dT as primer as described by Gubler and Hoffman (17). After ligation with the adaptor containing an EcoR1 site, the cDNA was ligated into lambda gt 10 to construct a carp ovarian cDNA library.

In order to isolate a cDNA encoding $\mathrm{p} 12$ from the carp ovarian cDNA library, we amplified a fragment of p12 cDNA 
by using polymerase chain reaction (PCR). Two primers, the forward, GTNGAT/CGCNGAT/CATT/CAAT/CGA and the reverse, AG/ANG/CA/TG/ATTNAACCANGGT/ CTG (where $N$ denotes $G, A$, T or $C$ ) were designed based on the degenerate codons of VDADIND and QPWLNSL of p12 determined by Edman degradation. Reagents for PCR were purchased from Promega Corporation and used according to the manufacturer's procedures. A DNA fragment of $280 \mathrm{bp}$ that contained a large portion of the open reading frame of p12 was thus amplified. This fragment was labeled by digoxigenin (Boehringer Mannheim, Mannheim, Germany) and used as a probe to screen the carp ovarian cDNA library.

For nucleotide sequencing, the cDNA insert was cut out of lambda gt 10 by EcoR 1 digestion and cloned into pUC19. The dideoxy chain termination method was used to determine the nucleotide sequence (34).

\section{Enzyme Inhibition Assay}

The apparent inhibition constant $\mathrm{K}_{\mathrm{i}(\text { app. }}$ of $\mathrm{p} 12$ on papain was determined as described by Nicklin and Barrett (29).

\section{Nucleic Acid Hybridization}

Twenty $\mu \mathrm{g}$ of total RNA were prepared from various tissues, denatured with formamide/formaldehyde and loaded onto an $1 \%$ agarose gel as described by Esch $e$ t al. (13). After electrophoresis, RNA was transferred to a nitrocellulose filter and hybridized with ${ }^{32} \mathrm{P}$-dATP-labeled cDNA encoding p12 prepared by nick translation using a $50 \%$ formamide $-5 x$ SSC- $5 x$ Denhardt solution at $42^{\circ} \mathrm{C}$ for $12 \mathrm{hr}$. After hybridization, the filter was washed twice with $0.1 \times$ SSC- $0.1 \%$ SDS at $42^{\circ} \mathrm{C}$ for 30 minutes. Autoradiography was then performed.

\section{Determination of Protein Content}

Protein content was determined as described by Bradford (7).

\section{RESULTS}

\section{Detection of Ovary-Specific Substances}

\section{Present in the Carp Ovarian Fluid by Western Blot}

The composition of carp ovarian fluid is complicated, consisting of several prominent and many minor electrophoretic bands as revealed by SDS-PAGE (Fig. 2d, lane 2). In order to determine which components are synthesized by the ovary as opposed to being derived from serum, a Western blot was performed on ovarian fluid using the antiserum against carp serum. Too many bands were stained making identification of nonreactive bands impossible (data not shown). Consequently, a partially purified fraction of ovarian fluid, that is, the flow through fraction of ovarian fluid from DEAE-TSK column was used (see below). When subjected to Western blotting using the above-mentioned antiserum, four immunologically nonreactive bands were identified. Their molecular weights were estimated to be $24,19,16$, and $12 \mathrm{kDa}$, respec- tively (Fig. 1). The $12 \mathrm{kDa}$ protein was selected for further analysis.

\section{Purification of $p 12$}

The $12 \mathrm{kDa}$ protein (denoted as $\mathrm{p} 12$ ) was purified as described in Materials and Methods. The results of DEAE-TSK, CMTSK and superdex $75 \mathrm{HR}$ chromatography were shown separately in Figs 2a, 2b and 2c. After superdex $75 \mathrm{HR}$ chromatography, p12 was revealed as a single band as analyzed by SDS-PAGE under nonreducing condition (Fig. 2d).

When the p12 obtained from a superdex $75 \mathrm{HR}$ column was subjected to amino-acid sequencing, two residues, in about equal amounts, were identified in each degradation step. This result suggests that the $\mathrm{p} 12$ thus purified may be a nicked protein containing two peptides held together by intramolecular linkages or represent two unrelated proteins. In order to examine further these two peptides or proteins, p12 was digested with trypsin. After separation by reverse-phase HPLC, four major peaks were selected for amino-acid sequencing. As shown in Fig. 3, two peaks (T-22 and T-27) have only one unique sequence whereas the other two peaks (T-19 and T-20) contain two sequences. The sample for amino-acid sequencing
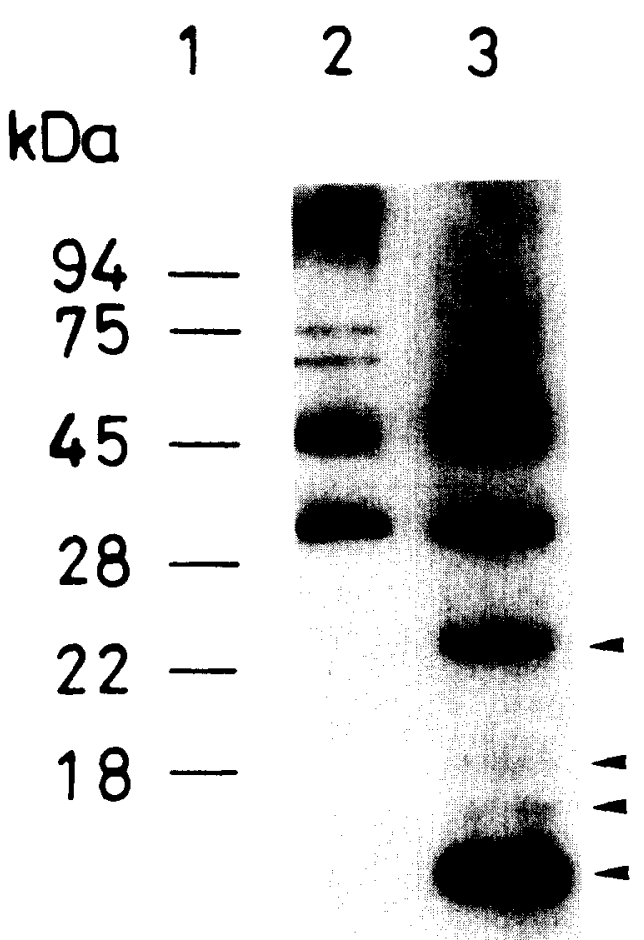

FIG. 1. Detection of ovary-specific substances from ovarian fluid by Western blot. For analysis, $10 \mu \mathrm{g}$ protein from peak 1 (the flow through fraction) of DEAE-TSK column chromatography was subjected to SDS-PAGE. The gel was resoluted by Western blot in which the antiserum against carp serum was used (lane 2) or stained by Coomassie Blue (lane 3). The immunologically unreactive bands in (lane 2) are marked by arrowheads. The prestained molecular weight markers are shown in lane 1. Other details are described in Materials and Methods. 

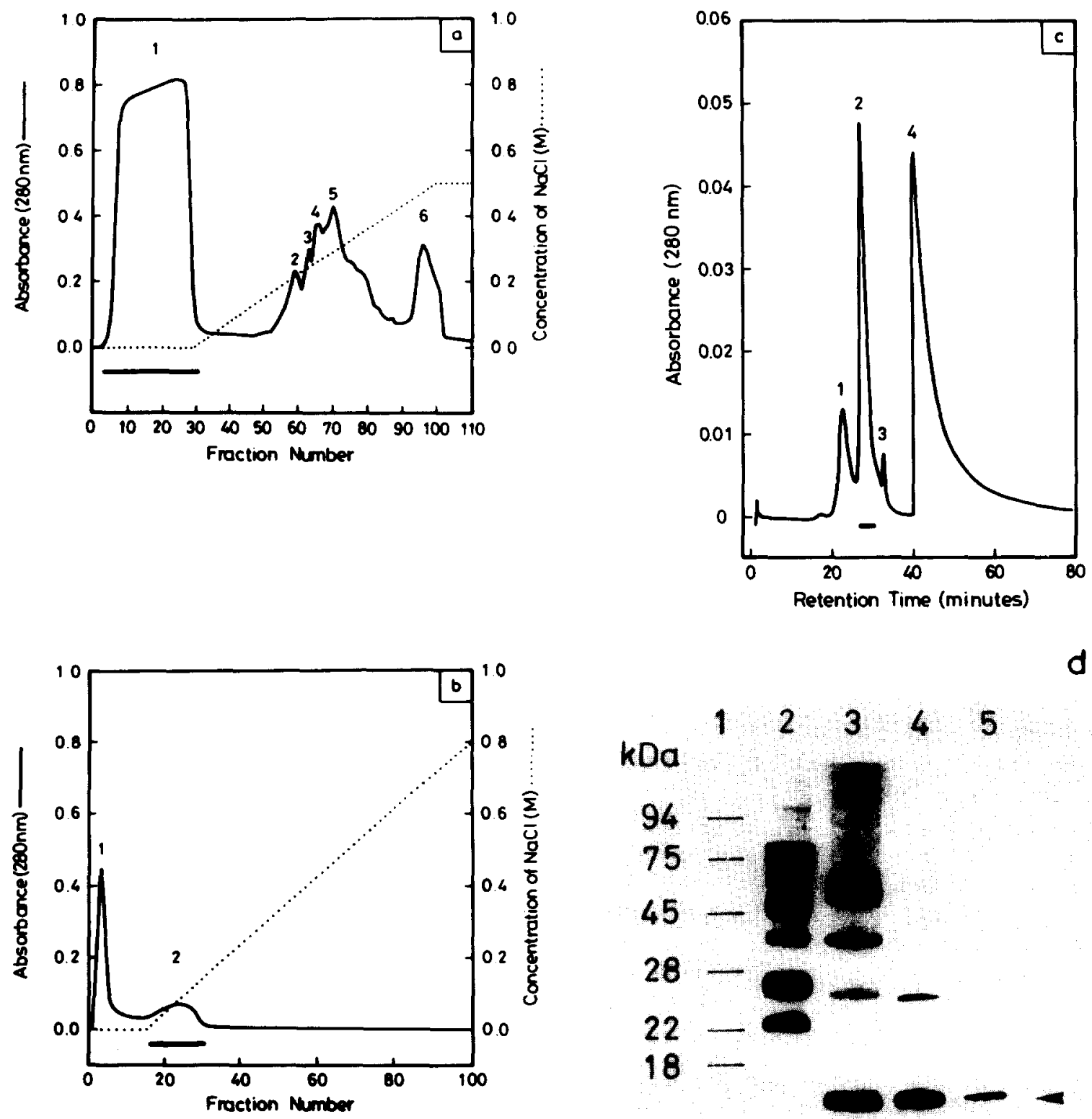

FIG. 2. Purification of p12 from carp ovarian fluid sequentially by chromatography of DEAE-TSK column (a), CM-TSK column (b), and superdex $75 \mathrm{HR}$ column (c). Fractions containing p12 in each purification step are marked by black horizontal bars. The SDS-PAGE profile of each purification step is shown in (d). Lane 1, prestained molecular weight markers; lane 2, crude ovarian fluid; lane 3, peak 1 from DEAE-TSK column; lane 4, peak 2 from CM-TSK column; lane 5, peak 2 from superdex 75 HR column. The p12 in (d) is indicated by arrowhead. Other details are described in Materials and Methods.

was not alkylated, therefore cysteine residues can not be identified by this method. When no residue is identified, it is assumed to be cysteine. A search (EMBL/Gene bank) determines that the sequence of $\mathrm{T}-27$ was homologous to the cystatin of puffer adder (32) and chicken $(10,37)$. This finding suggests that $\mathrm{p} 12$ may be a carp cystatin also.

On the assumption that $\mathrm{p} 12$ is a cystatin, we consequently allocated one of the two residues of the $\mathrm{N}$-terminal sequences of $\mathrm{p} 12$ and those of T-19 and T-20 into separated sequences to match maximally with the known cystatin sequences. The results shown in Fig. 3 indicate that the allocated $N$-terminal sequences of $\mathrm{p} 12(\mathrm{~N}-\mathrm{a}$ and $\mathrm{N}-\mathrm{b})$ and those of trypsin digests
(T-19a and T-19b) are also homologous to cystatins of other species. The above data reinforce the possibility that $\mathrm{p} 12$ is a carp cystatin.

\section{Characterization of $p 12$}

Purified $\mathrm{p} 12$ inhibits the enzymatic activity of papain, a cysteine protease with an apparent inhibition constant, $K_{i(a p p)}$ of $0.01 \mathrm{nM}$ (data not shown).

The p12 reveals only a single band in SDS-PAGE in the absence of reducing agent. When reduced using $3 \% \beta$ mercaptoethanol treatment, the $12 \mathrm{kDa}$ band disappears com- 


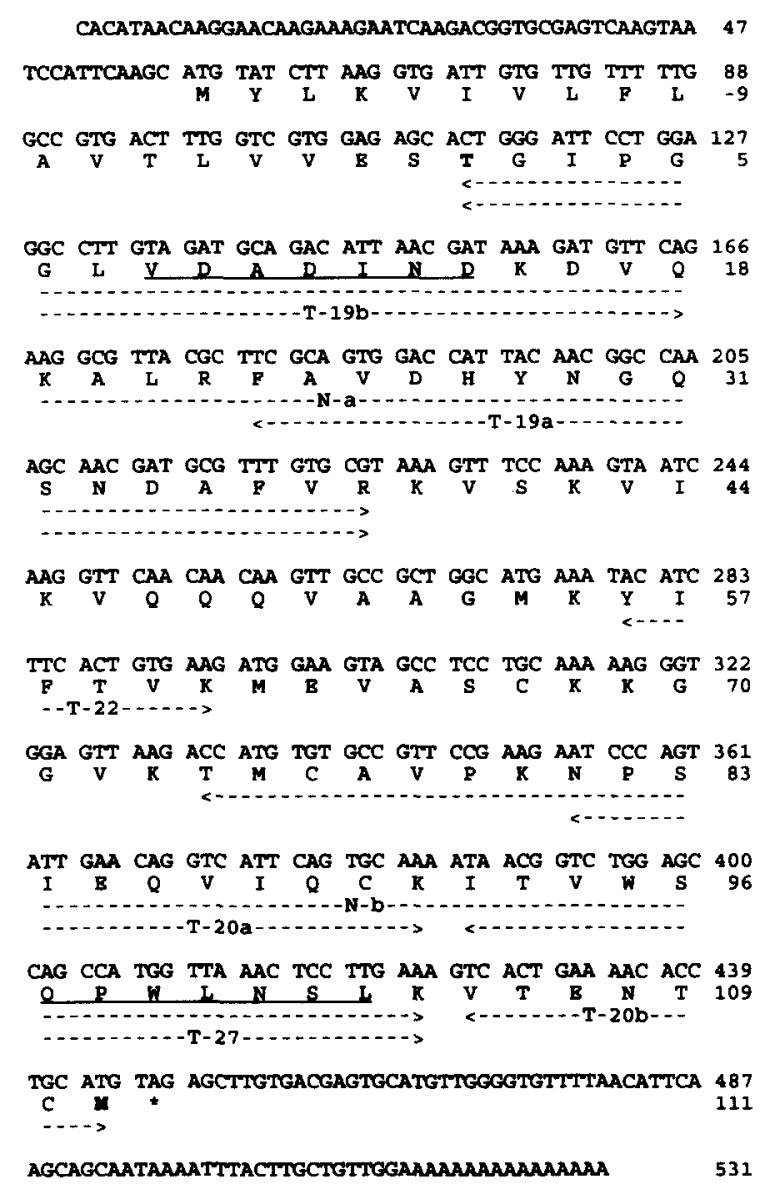

FIG. 3. The nucleotide sequence and the deduced amino-acid sequence of the cDNA encoding p12 and the partial sequences of 12 determined by Edman degradation. Both the nucleotide and the amino-acid sequence are numbered. The residues of the signal peptide and the mature protein are indicated by negative and positive numbers, respectively. The stop codon is indicated by *. The degenerate codons used for designing the forward and reverse primer for PCR are underlined. The partial sequences of p1 2 determined by Edman degradation are indicated by broken lines. When two residues appear in the same sequencing step, they are allocated to match with the aminoacid sequence deduced from the nucleotide sequence of the cDNA encoding p12. The $N$ - and $C$-terminus are indicated by bold-faced letters. The samples for Edman degradation are not alkylated, therefore cysteine residue can not be identified. When no residue is identified in a given sequencing step, it is assumed to be cysteine.

pletely and two bands of 5 and $7 \mathrm{kDa}$ are seen (Fig. 4). The $7 \mathrm{kDa}$ band can be visualized clearly but the $5 \mathrm{kDa}$ band was stained weakly by Coomassie Blue. The two bands were blotted to a ProBlott membrane and partial sequences determined. The sequence of $7 \mathrm{kDa}$ is TGIPG whereas that of $5 \mathrm{kDa}$ is TMCAVPKNPS. These two partial sequences are identical to the two $N$-terminal sequences found for p12 (see Fig. 3 , $N$-a and $N-b$ ). This result suggests the possibility that p12 is a nicked protein in which the two peptides are held together possibly by intramolecular disulfide bond.

\section{Molecular Cloning of $\mathrm{p} 12$}

Among the sequences of p12 obtained, the sequences VDADIND and QPWLNSL are the most conserved and are located respectively at the $N$ - and C-terminal regions when compared with family 2 cystatins of other species. Consequently, degenerate codons representing those peptide fragments were used to design the forward and reverse primers for PCR amplification of a fragment of cDNA encoding $\mathrm{p} 12$. When the cDNA prepared from carp ovary was used as template, a fragment of cDNA of $278 \mathrm{bp}$ was amplified. Its deduced amino-acid sequence includes most of the sequences of $N-a, N-b, T-19 b$ and $T-27$ and all the sequences of T-19a, T-20a and T-22 (Fig. 3).

In order to elucidate the primary structure of $\mathrm{p} 12$, we used the above cDNA fragment as a probe to screen the carp ovarian cDNA library. After screening $1 \times 10^{5}$ plaques, we obtained six positive plaques. All contained an identical insert.

The p12 cDNA is 531 bp in length (Fig. 3). It consists of a $5^{\prime}$ untranslated region of $58 \mathrm{bp}$, an open reading frame of $387 \mathrm{bp}$ and a 3' untranslated region of $83 \mathrm{bp}$ with a polyadenylation signal and a polyadenylated tract. The amino-acid sequence deduced from the cDNA encompasses all of the partial amino-acid sequences of $\mathrm{p} 12$ determined by Edman degradation. The $\mathrm{N}$ - and $\mathrm{C}$-terminus of $\mathrm{p} 12$ are threonine and methionine, respectively. The mature protein of p1 2 contains
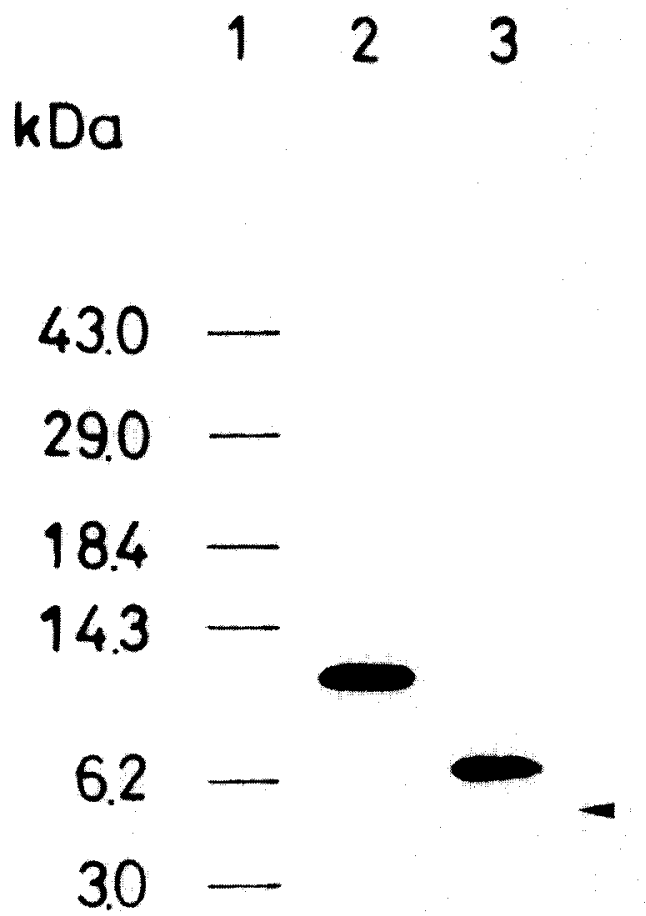

FIG. 4. The SDS-PAGE profile of native and reduced p12. Lane 1 , prestained molecular weight markers; lane $2,5 \mu \mathrm{g}$ of native p12; lane 3, $5 \mu \mathrm{g}$ of p12 treated with $3 \% \beta$-mercaptoethanol. Gel is stained by Coomassie Blue. The reduced p12 in lane 3 has 2 bands of 5 and $7 \mathrm{kDa}$. The band of $5 \mathrm{kDa}$ is faintly stained and is indicated by arrowhead. 
111 residues and the precursor of $\mathrm{p} 12$ has a signal peptide of 18 residues.

\section{Expression of Cystatin in Carp}

Northern blot analysis reveals that the expression of $\mathrm{p} 12$ in carp is ovary specific. It can only be detected in RNA prepared from ovary but not from brain, head kidney, intestine, kidney, liver, spleen or testis (Fig. 5). Western blot analysis also reveals that $\mathrm{p} 12$ can only be detected in ovary but not in the brain, head kidney, intestine, kidney, liver, semen, serum, spleen and testis of carp (data not shown).

\section{DISCUSSION}

The p12 was purified through several types of column chromatography and found to inhibit the enzymatic activity of papain. Its primary structure was partially determined by Edman degradation and fully elucidated by molecular cloning. When the primary structure of $\mathrm{p} 12$ is compared with other family 2 cystatins, the following homologies are observed (Fig. 6): 46\% to chum salmon cystatin (26), 44\% to puff adder cystatin (32), $38 \%$ to chicken cystatin $(10,37), 34 \%$ to bovine cystatin (21) and 28 to $34 \%$ to human cystatin C, S, SA-I and SN $(2,5,15,16,23,24,25,30,33)$. The following common features are observed among them. (1) They consist of 110 to 120 amino-acid residues $(3,4,39)$. (2) They have 4 cysteine residues with the potential to form 2 disulfide bonds $(3,4,39)$. (3) An invariant glycine residue is present in the protease contact area, which is located in the $N$-terminal part of the molecule $(6,39)$. (4) A consensus sequence of $G \ln -x-x-x-G l y$ ( $x$ for any residue) is present in the middle part of the molecule $(6,39)$. (5) A sequence of Pro-Trp is present in the Cterminal part of the molecule $(6,39)$. For p12 and the family 2 cystatins of other species, all the conserved residues men-

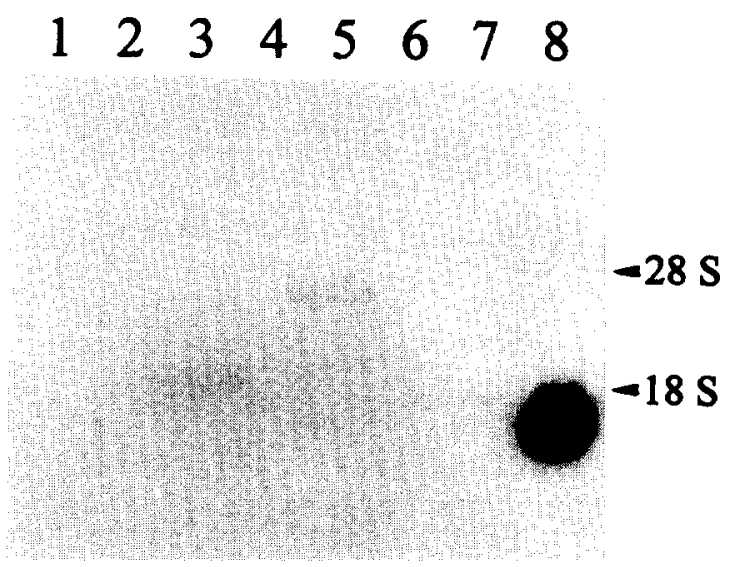

FIG. 5. Tissue-specific expression of carp cystatin. Blots were prepared with $20 \mu \mathrm{g}$ total RNA from each tissue and probed with carp cystatin cDNA. The position of $28 S$ and $18 S$ rRNA are indicated. Lane 1, brain; lane 2, head kidney; lane 3, intestine; lane 4, kidney; lane 5, liver; lane 6, spleen; lane 7, testis; lane 8 , ovary.

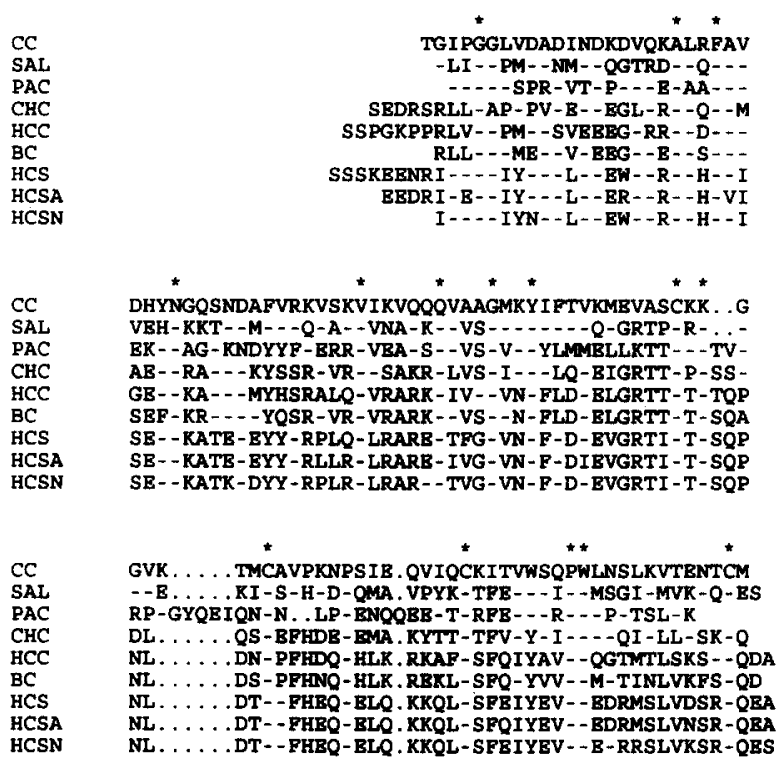

FIG. 6. Comparison of the primary structure of $\mathrm{p} 12$ with those of family 2 cystatins of other species. For maximal alignment, blanks are inserted as represented by dots. Dashes represent the identical residues to those of p12. The invariant residues among p12 and the family 2 cystatins of other species are indicated by *. Abbreviations: CC, carp cystatin; SAL, chum salmon cystatin; PAC, puff adder cystatin; $\mathrm{CHC}$, chicken cystatin; HCC, human cystatin $\mathrm{C}$; BC, bovine cystatin; HCS, human cystatin S; HCSA, human cystatin SA; HCSN, human cystatin SN.

tioned above can be aligned. Based on these functional and structural properties, $\mathrm{p} 12$ should be considered a member of family 2 cystatin.

Western blot analysis using antiserum against $\mathrm{p} 12$ revealed that a protein of $12 \mathrm{kDa}$ is present in ovarian extract under reducing condition (data not shown). However, p12 has two $\mathrm{N}$-terminal sequences of equal molar ratio. Furthermore, in the absence of reducing agent, p12 displayed a single band of $12 \mathrm{kDa}$ in SDS-PAGE. When p12 was reduced by $\beta$ mercaptoethanol, the band of $12 \mathrm{kDa}$ was not seen but two new bands of 5 and $7 \mathrm{kDa}$ appeared (Fig. 4). Therefore, we speculate that $\mathrm{p} 12$ is a nicked protein cleaved by a specific protease present in ovarian fluid. Judging from the two partial $\mathrm{N}$-terminal sequences of $\mathrm{p} 12$, cleavage occurs at the peptide bond between lysine and threonine of residue 73 and 74 to generate two peptides. We assume that the two peptides of p12 are held together by intramolecular disulfide bond. This is consistent with the fact that $\mathrm{p} 12$ has four cysteines in which one residue is present in the $\mathrm{N}$-terminal fragment of the first 73 residues with the remaining three residues present in the C-terminal fragment of the last 38 residues. The single cysteine residue present in the $N$-terminal fragment could form a disulfide bond with one of the three cysteine residues present in the C-terminal fragment, thus linking the two peptides.

Despite the fact that p12 is composed of two peptides, it 
still possesses inhibitory activity on papain. A similar situation exists with Kunitz-type soybean trypsin inhibitor (27).

Both Northern and Western blot analyses reveal that p12 is synthesized and accumulated in the carp ovary. Such a specific expression and restricted distribution were also observed in human cystatin D, S, SA and SN $(5,14,24,25)$. On the contrary, human cystatin $\mathrm{C}$ distributes widely in various tissues and body fluids (1). In addition to the tissue-specific distribution, cystatins have different inhibitory activity on different cysteine protease (24). Therefore, each type of cystatin may have its unique physiological function. Recently, it has been demonstrated that the cystatin activity of various tissues is changed during feeding and spawning migrations of chum salmon, suggesting a relationship between cystatin activity and physiological conditions (41). It is inferred that the restricted distribution of $\mathrm{p} 12$ may have important ovarian function. Currently we are investigating a papain-like protease from carp ovarian fluid in an effort to determine the physiological roles played by this protease and its possible inhibitor, p12.

\section{References}

1. Abrahamson, M.; Olafsson, I.; Palsdottir, A.; Ulvsback, M.; Lundwall, A.; Jensson, O.; Grubb, A. O. Structure and expression of the human cystatin $\mathrm{C}$ gene. Biochem. J. 268:287$294 ; 1990$

2. Al-Hashimi, I.; Dickinson, D. P.; Levine, M. J. Purification, molecular cloning, and sequencing of salivary cystatin SA-I. J. Biol. Chem. 263:9381-9387;1988.

3. Barrett, A. J.; Fritz, H.; Grubb, A.; Isemura, S.; Järvinen, M.; Katunuma, N.; Machleidt, W.; Müller-esterel, W.; Sasaki, M.; Turk, V. Nomenclature and classification of the proteins homologous with the cysteine-proteinase inhibitor chicken cystatin. Biochem. J. 236:311-312;1986.

4. Barrett, A. J.; Rawlings, N. D.; Davies, M. E.; Machleidt, W.; Salvesen, G.; Turk, V. In: Barrett, A. J.; Salvesen, G., eds. Proteinase inhibitors. Amsterdam: Elsevier Scientific Publishing Co.; 1986:515-569.

5. Bobek, L. A.; Aguirre, A.; Levine, M. J. Human salivary cystatin S. Biochem. J. 278:627-635;1991.

6. Bode, W.; Engh, R.; Musil, D.; Thiele, U.; Huber, R.; Karshikov, A.; Brzin, J.; Kos, J.; Turk, V. The $2.0 \AA$ X-ray crystal structure of chicken egg white cystatin and its possible mode of interaction with cysteine proteinases. EMBO J. 7:2593$2599 ; 1988$

7. Bradford, M. B. A rapid and sensitive method for the quantitation of microgram quantities of protein utilizing the principle of protein-dye binding. Anal. Biochem. 72:248-254;1976.

8. Chang, Y. S.; Huang, F. L. Reproduction physiology of whitespotted freshwater catfish. II. The histological and biochemical changes of eggs during maturation induced by carp pituitary gland extract. J. Fish. Soc. Taiwan 4:1-10;1976.

9. Chomczynski, P.; Sacchi, N. Single-step method of RNA isolation by acid guanidinium thiocyanate-phenol-chloroform extraction. Anal. Biochem. 162:156-159;1987.

10. Colella, R.; Sakaguchi, Y.; Nagase, H.; Bird, J. W. C. Chicken egg white cystatin. J. Biol. Chem. 264:17164-17169;1989.

11. Curry, T. E.; Dean, D. D.; Sanders, S. L.; Pedigo, N. G.; Jones, P. C. The role of ovarian proteases and their inhibitors in ovulation. Steroids 54:501-521;1989.

12. Curry, T. E.; Sanders, S. L.; Pedigo, N. G.; Estes, R. S.; Wil- son, E. A.; Vernon, M. W. Identification and characterization of metalloproteinase inhibitor activity in human ovarian follicular fluid. Endocrinology 123:1611-1618;1988.

13. Esch, F. S.; Mason, A. J.; Cooksey, K.; Mercado, M.; Shimasaki, S. Cloning and DNA sequence analysis of the cDNA for the precursor of the $\beta$ chain of bovine follicle stimulating hormone. Proc. Natl. Acad. Sci. USA 83:6618-6621;1986.

14. Freije, J. P.; Abrahamson, M.; Olafsson, I.; Velasco, G.; Grubb, A.; Lopez-Otin, C. Structure and expression of the gene encoding cystatin $D$, a novel human cysteine proteinase inhibitor. $J$ Biol. Chem. 266:20539-20543;1991.

15. Grubb, A.; Löfberg, H. Human $\tau$-trace, a basic microprotein: amino acid sequence and presence in the adenohypophysis. Proc. Natl. Acad. Sci. USA 79:3024-3027;1982.

16. Grubb, A.; Löfberg, H.; Barrett, A. J. The disulphide bridges of human cystatin $\mathrm{C}(\tau$-trace) and chicken cystatin. FEBS Lett. 170:370-374;1984

17. Gubler, U.; Hoffman, B. J. A simple and very efficient method for generating cDNA libraries. Gene 25:263-269;1983.

18. Hamabata, T.; Okimura, H.; Yokoyama, N.; Takahashi, T.; Takahashi, K. Purification, characterization, and localization of follipsin, a novel serine proteinase from the fluid of porcine ovarian follicles. J. Biol. Chem. 269:17899-17904;1994.

19. Harlow, E.; Lane, D. In: Harlow, E.; Lane, D., eds. Antibodies. A laboratory manual. New York: Cold Spring Harbor Laboratory; 1988:53-137.

20. Hewick, R. M.; Hunkapiller, M. W.; Hood, L. E.; Dreyer, W. J. A gas-liquid solid phase peptide and protein sequenator. J. Biol. Chem. 256:7990-7997;1981.

21. Hirado, M.; Tsunasawa, S.; Sakiyama, F.; Niinobe, M.; Fujii, $\mathrm{S}$. Complete amino acid sequence of bovine colostrum low-M cysteine proteinase inhibitor. FEBS Lett. 186:41-45:1985.

22. Ichimura, T.; Sugano, H.; Kuwano, R.; Sunaya, T.; Okuyama, $T$.; Isobe, T. Widespread distribution of the $14-3-3$ protein in vertebrate brains and bovine tissues: correlation with the distributions of calcium-dependent protein kinases. J. Neurochem. 56:1449-1451;1991.

23. Isemura, S.; Saitoh, E.; Sanada, K. Isolation and amino acid sequence of SAP-1, an acidic protein of human whole saliva, and sequence homology with human $\tau$-trace. J. Biochem. 96 : $489-498 ; 1984$.

24. Isemura, S.; Saitoh, E.; Sanada, K. Characterization of a new cysteine proteinase inhibitor of human saliva, cystatin SN, which is immunologically related to cystatin S. FEBS Lett. 198: $145-149 ; 1986$.

25. Isemura, S.; Saitoh, E.; Sanada, K. Characterization and amino acid sequence of a new acidic cysteine proteinase inhibitor (Cystatin SA) structurally closely related to cystatin S, from human whole saliva. J. Biochem. 102:693-704;1987.

26. Koide, Y.; Noso, T. The complete amino acid sequence of pituitary cystatin from chum salmon. Biosci. Biotech. Biochem. 58 $164-169 ; 1994$

27. Laskowski, M., Jr.; Kato, I. Protein inhibitors of proteinases. Ann. Rev. Biochem. 49:593-626;1980.

28. LeMaire, W. J. Mechanism of mammalian ovulation. Steroids $54: 455-469 ; 1989$.

29. Nicklin, M. J. H.; Barrett, A. J. Inhibition of cysteine proteinase and dipeptidyl peptidase I by egg-white cystatin. Biochem. J. 223:245-253;1984.

30. Rawlings, N. D.; Barrett, A. J. Evolution of proteins of the cystatin superfamily. J. Mol. Evol. 30:60-71;1990.

31. Reim, D. F.; Speicher, D. W. Microsequence analysis of electroblotted proteins. Anal. Biochem. 207:19-23;1992.

32. Ritonja, A.; Evans, H. J.; Machleidt, W.; Barrett, A. J. Amino acid sequence of a cystatin from venom of the African puff adder (Bitis arietans). Biochem. J. 246:799-802;1987. 
33. Saitoh, E.; Isemura, S.; Sanada, K.; Kim, H. S.; Smithies, O.; Maeda, N. Cystatin superfamily. Biol. Chem. Hoppe-Seyler 369:191-197;1988.

34. Sanger, F.; Nicklen, S.; Coulson, A. R. DNA sequencing with chain-terminating inhibitors. Proc. Natl. Acad. Sci. USA 74: $5463-5467 ; 1977$.

35. Sappino, A. P.; Huarte, J.; Belin, D.; Vassalli, J. D. Plasminogen activators in tissue remodeling and invasion: mRNA localization in mouse ovaries and implanting embryos. J. Cell Biol. 109:2471-2479;1989.

36. Schägger, H.; Jagow, G. V. Tricine-sodium dodecyl sulfatepolyacrylamide gel electrophoresis for the separation of proteins in the range from 1 to $100 \mathrm{kDa}$. Anal. Biochem. 166:368$379 ; 1987$.

37. Schwabe, C.; Anastasi, A.; Crow, H.; McDonald, J. K.; Barrett, A. J. Cystatin, amino acid and possible secondary structure. Biochem. J. 217:813-817;1984.
38. Tanaka, N.; Espey, L. L.; Okamura, H. Increase in ovarian blood volume during ovulation in the gonadotropin-primed immature rat. Biol. Reprod. 40:762-768;1989.

39. Turk, V.; Bode, W. The cystatins: protein inhibitors of cysteine proteinases. FEBS Lett. 285:213-219;1991.

40. Watanabe, W. O.; Kuo, C. M. Water and ion balance in hydrating oocytes of the grey mullet, Mugil cephalus L., during hormone-induced final maturation. J. Fish Biol. 28:423437;1986.

41. Yamashita, M.; Konagawa, S. A comparison of cystatin activity in the various tissues of chum salmon Onchorhynchus keta between feeding and spawning migrations. Comp. Biochem. Physiol. 100A:749-751;1991.

42. York, W. S.; Patiño, R.; Thomas, P. Ultrastructural changes in follicle cell-oocyte associations during development and maturation of the ovarian follicle in Atlantic croaker. Gen. Comp. Endocrinol. 92:402-418;1993. 